\title{
Assessing the flow characteristics of nanofluids during turbulent natural convection
}

\author{
K. Kouloulias ${ }^{1} \cdot$ A. Sergis ${ }^{1} \cdot$ Y. Hardalupas ${ }^{1}$
}

Received: 13 January 2018 / Accepted: 2 August 2018/Published online: 14 August 2018

(C) The Author(s) 2018

\begin{abstract}
High-performance cooling is of vital importance for the cutting-edge technology of today, from nanoelectronic mechanical systems to nuclear reactors. Advances in nanotechnology have allowed the development of a new category of coolants, termed nanofluids that have the potential to enhance the thermal performance of conventional heat transfer fluids. At the present time, nanofluids are a controversial research theme, since there is yet no conclusive answer to explain the underlying physical mechanisms of heat transfer. The current study investigates experimentally the heat and mass transfer behaviour of dilute $\mathrm{Al}_{2} \mathrm{O}_{3}-\mathrm{H}_{2} \mathrm{O}$ nanofluids under turbulent natural convection-Rayleigh number of the order of $10^{9}-\mathrm{in}$ a cubic Rayleigh-Bénard cell with optical access. Traditional heat transfer measurements were combined with a velocimetry method to obtain a deeper understanding of the impact of nanoparticles on the heat transfer performance of the base fluid. Particle image velocimetry was employed to quantify the resulting mean velocity field and flow structures in dilute nanofluids under natural convection, at three parallel planes inside the cubic cell. All the results were compared with that for the base fluid, i.e. deionised water. It was observed that the presence of a minute amount of $\mathrm{Al}_{2} \mathrm{O}_{3}$ nanoparticles in deionised water, $\varphi_{\mathrm{v}}=0.00026 \mathrm{vol} . \%$, considerably modifies the mass transfer behaviour of the fluid in the bulk region of turbulent Rayleigh-Bénard convection. Simultaneously, the general heat transport, as expressed by the Nusselt number, remained unaffected within the experimental uncertainty.
\end{abstract}

Keywords Nanofluids · Cooling · Turbulent natural convection · Rayleigh-Bénard · Particle image velocimetry · Large-scale circulation

\section{List of symbols}

$|V|_{\text {avg }} \quad$ Temporally averaged absolute velocity $\left(\mathrm{cm} \mathrm{s}^{-1}\right)$

$\overline{|V|_{\text {avg }}}$ Spatially and temporally averaged absolute velocity $\left(\mathrm{cm} \mathrm{s}^{-1}\right)$

$\delta \overline{|V|_{\text {avg }}}$ Percentage increase of the spatially and temporally averaged absolute velocity

$|V|_{\text {avg-max }} \quad$ Maximum temporally averaged absolute velocity $\left(\mathrm{cm} \mathrm{s}^{-1}\right)$

$H \quad$ Height of field of view (mask) $(\mathrm{mm})$

$h \quad$ Heat transfer coefficient $\left(\mathrm{W} \mathrm{m}^{-2} \mathrm{~K}^{-1}\right)$

$L \quad$ Characteristic length (m)

$\mathrm{Nu} \quad$ Nusselt number

Pr Prandtl number

$q^{\prime \prime} \quad$ Heat flux $\left(\mathrm{kW} \mathrm{m}^{-2}\right)$

K. Kouloulias

k.kouloulias13@imperial.ac.uk

1 Mechanical Engineering Department, Imperial College London, London SW7 2AZ, UK
Ra Rayleigh number

Stdev Spatially and temporally averaged standard deviation of the turbulent velocity fluctuations $\left(\mathrm{cm} \mathrm{s}^{-1}\right)$

$T \quad$ Temperature $\left({ }^{\circ} \mathrm{C}\right)$

$T_{\mathrm{c}} \quad$ Temperature at the wetted surface of the cooling plate $\left({ }^{\circ} \mathrm{C}\right)$

$W \quad$ Width of the field of view (mask) (mm)

$\Delta T_{\mathrm{h}, \mathrm{c}} \quad$ Temperature difference between the heating and cooling plates $\left({ }^{\circ} \mathrm{C}\right)$

\section{Greek symbols}

$\Gamma \quad$ Aspect ratio

$\varphi_{\mathrm{v}} \quad$ Nanoparticle volume fraction

\begin{tabular}{ll}
\multicolumn{2}{l}{ Subscripts } \\
avg & Average \\
c & Cooling plate \\
h & Heating plate \\
v & Volume
\end{tabular}

Subscripts

avg Average

h Heating plate 


\section{Abbreviations}

DI Deionised water

HGS Hollow glass spheres

LSC Large-scale circulation

PIV Particle image velocimetry

RB Rayleigh-Bénard

RBC Rayleigh-Bénard convection

TEM Transmission electron microscopy

\section{Introduction}

Nanofluids represent a new category of nanotechnologybased fluids engineered by dispersing and stably suspending nanosized particles, fibres or tubes in traditional heat transfer fluids. The employed nanoparticles can be metallic, non-metallic or carbon nanotubes and are dispersed in base fluids, such as water, ethanol, ethylene glycol and engine oil [1-3]. The novelty behind nanofluids is the high surface-to-volume ratio of nanoparticles that is orders of magnitude higher than that of larger particles, such as by millimetre- and micrometre-sized particles. As a consequence, the high surface area of nanoparticles was suggested to lead to an enhanced thermal conductivity in nanofluids, since more solid surface can take part in heat transfer [4]. Up to the present, nanofluids have attracted significant attention $[5,6]$, due to their intriguing heat transfer properties under various heat transfer modes and their potential use in a broad range of applications [7, 8].

According to an extended statistical analysis of data available in the literature, the heat transfer enhancement when nanofluids are involved is $5-9 \%$ for the conductive heat transfer, $10-14 \%$ for the mixed conductive-convective, $40-44 \%$ for pool boiling and up to $200 \%$ increase for the value of the critical heat flux [9]. Despite the reported promising heat transfer characteristics of nanofluids, the physical understanding of the underlying processes is missing [10], and a controversy remains regarding their capability and applicability in engineering applications. This controversy arises from inconsistency in the observations of reported studies, accompanied by insufficient understanding of the physical mechanisms involved in nanofluids. For example, while heat transfer enhancement is reported for forced convection [11-14], opposing results are observed for natural convection with additional puzzling discrepancy [15] between numerical [16-19] and experimental $[2,20-22]$ natural convection studies.

An attractive way to assess the heat and mass transport mechanisms in nanofluids is by experimentation under different heat transfer modes that meet extensive applicability in nature and engineering systems. One example is natural convection where only gravitational and buoyant forces are present. Given the controversy among the convection studies in nanofluids, there is an additional motivation to exploit the heat and mass transfer properties of nanofluids under natural convection that is of primary significance for numerous applications in engineering [23], atmospheric and oceanic sciences [24, 25].

Convection is in general the transport of energy due to random molecular motion (energy diffusion) and bulk, or macroscopic, motion (advection). It is the progression of conduction when the temperature variations in a fluid are large enough to overcome its resistance to motion. Convection can be classified, according to the nature of the flow, to forced convection and free or natural convection. In forced convection, the flow is caused by external means, such as a fan or a pump. In natural convection, the flow is induced by buoyant forces due to density differences, caused by temperature variations in the fluid. One of the most established models to study buoyancy-driven flows and the associated heat and mass transport mechanisms is Rayleigh-Bénard convection (RBC). This involves the use of a relatively simple apparatus, though characterised by increased controllability, known as Rayleigh-Bénard (RB) cell.

A typical RB cell is a closed system that contains a fluid, confined between two horizontal parallel plates at a distance $L$ apart. The fluid is heated from the lower plate and cooled from the upper plate, while the insulated side walls complete the set-up. For the study of RBC, different RB cells have been employed that vary in aspect ratio $\Gamma$, shape, design and construction materials. Studies of natural convection in RB cells have been conducted for low, moderate $\left(\sim 10^{5}\right)$ and high Rayleigh numbers $\left(>10^{7}\right)$ over a broad range of operating conditions. Based on the resulting flow conditions, two types of natural convection are distinguished: laminar and turbulent. Turbulent natural convection has mostly attracted the scientific interest, due to the complex features associated with turbulence, and the resulting increased heat and mass transfer rates that have been reported [26].

In turbulent convection, two discrete states have been identified according to the Rayleigh number, Ra, of the flow and the aspect ratio, $\Gamma$, of the employed cell. In cells with aspect ratios close to unity, a soft turbulent state has been observed for $\mathrm{Ra}<10^{7}$ and hard turbulent state for $\mathrm{Ra}$ between $4 \times 10^{7}$ to $10^{12}$ [27-29], with the difference lying on the way in which the thermals and plumes develop and traverse inside. It has been widely reported that, at the hard turbulent state, a large-scale coherent flow exists [30-32], which is self-organised by the hot rising and cold falling plumes. This flow mode is known as mean wind or largescale circulation (LSC). Figure 1 illustrates a two-dimensional sketch of a typical cubic RB cell, along with the LSC. Up to date, the LSC remains an attractive feature to study and further analyse, as the heat transport in turbulent 


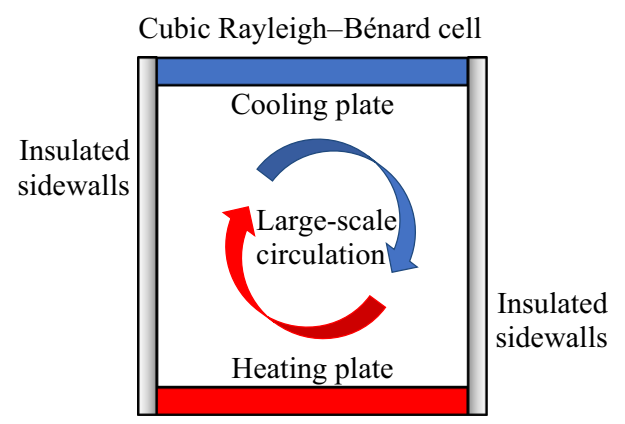

Fig. 1 Schematic drawing of a cubic Rayleigh-Bénard cell, depicting the large-scale circulation

natural convection takes place primarily along the periphery of the cell, in the direction of the LSC [33]. In the present study, traditional heat transfer measurements in combination with a velocimetry method are applied to study the heat transfer mechanisms in nanofluids under turbulent RBC. The study of nanofluids under RBC by focusing on the LSC is an effective way to assess the heat transfer properties of these new coolants, establish the underlying physical mechanisms and try to resolve the discrepancy among the natural convection studies. Up to the authors' knowledge, this is the first available study, given the complexity of employing a high-spatial-resolution flow velocimetry method in nanofluids under turbulent conditions and the challenge of visualising the resulting LSC experimentally.

\section{Experimental}

\section{Experimental set-up}

A classical Rayleigh-Bénard (RB) cell configuration with optical access is operated in the current study. Figure $2 \mathrm{a}$ shows a schematic drawing of the RB cell, including all the major components. A detailed description of this configuration is given in Ref. [2], while a brief overview of its components is included herein. The cell consists of a heating plate, A, at the bottom, a cooling plate, B, at the top and lateral walls, C. It incorporates four quartz windows, 2 square $(40 \mathrm{~mm} \times 40 \mathrm{~mm})$ and 2 rectangular $(10 \mathrm{~mm} \times$ $40 \mathrm{~mm}$ ), D, to allow laser-based visualisation studies. Teflon plates, E, are inserted among all the conductive components to prevent their thermal connection. Finally, insulating pans, F, and a Plexiglas cover, G, are placed outside the core of the cell to eliminate heat losses from the sides. A second set of heating elements $\mathrm{H}$ is placed below the heating plate to prevent any heat losses downwards. The operation of the RB cell is monitored and controlled through LabVIEW software, coupled with National Instruments hardware and an in-house electrical device that is connected to the heating plates $(\mathrm{A}, \mathrm{H})$ and thermocouples placed in the cell.

\section{Particle Image Velocimetry}

Particle image velocimetry (PIV) allows instantaneous planar measurements of the temporal and spatial distribution of the flow velocity in transparent and semi-transparent fluids. PIV has been already employed to investigate flows of dilute nanofluids (semi-transparent fluids) inside various systems, such as a HyperVapotron [34] and a pool boiling apparatus [35]. The PIV technique relies on the use of a laser source to illuminate twice, with a fixed time interval, micron-sized tracer (seeding) particles dispersed in the flow, on planes defined by a thin laser sheet.

In the current study, PIV was employed for DI water and dilute $\mathrm{Al}_{2} \mathrm{O}_{3}-\mathrm{H}_{2} \mathrm{O}$ nanofluids inside the cubic $\mathrm{RB}$ cell, through the available optical access. A double-pulsed Nd:YAG laser (Nano T 135-15 PIV) was involved, along
Fig. 2 Schematic drawing of the (a) Rayleigh-Bénard cell and (b) field of view (mask) for the laser-based particle image velocimetry measurements (a)

(b)

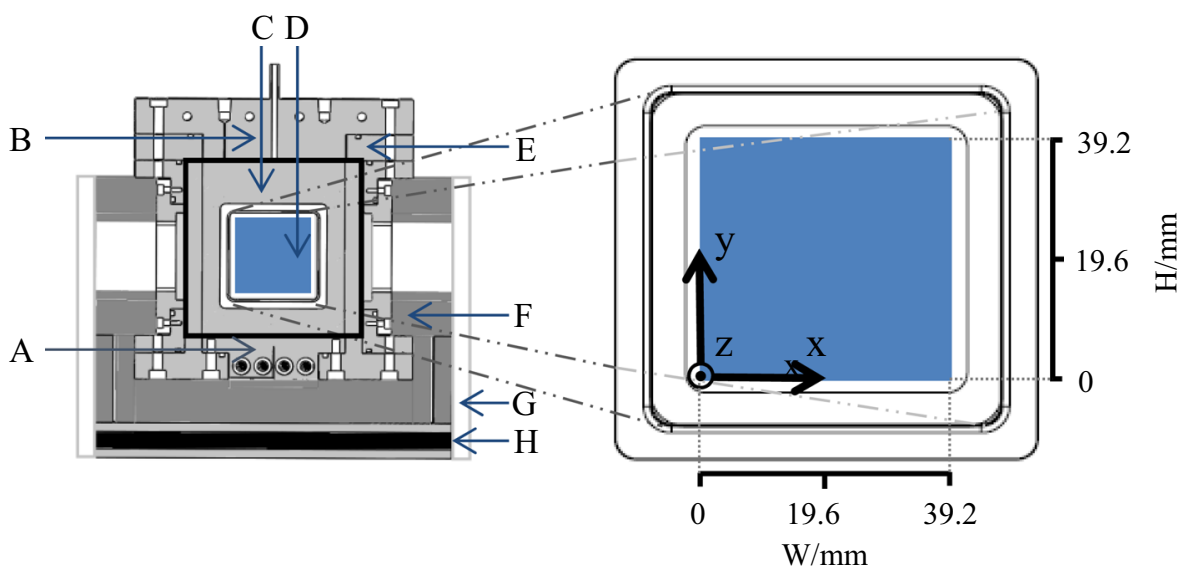


with a charge-coupled device (CCD) camera (Imager Intense, LaVision) that was placed perpendicular to the laser sheet. The CCD camera has a spatial resolution of $1376 \times 1040$ pixel, and it was used to record the displacement of the seeding particles between the two laser pulses. A Nikon AF Nikkor $50 \mathrm{~mm}$ f/1.4D lens with manual focus was mounted to the camera. Additionally, a bandpass filter $(10 \mathrm{~nm}$ bandwidth, $532 \mathrm{~nm}$ centre wavelength) was attached to the lens to provide enhanced isolation of the Nd:YAG laser light and excellent suppression in the blocking region.

Hollow glass spheres, HGS (80A6011, Dantec Dynamics), with a nominal diameter of $10 \mu \mathrm{m}$ and a density of $1100 \mathrm{~kg} \mathrm{~m}^{-3}$ were used as seeding particles. Specifically, a small amount of HGS $\varphi_{\mathrm{v}}=0.00045$ vol.\% (as calculated through an optimisation study) is enough to ensure appropriate and accurate tracking of the fluid flow, while avoiding any possible change in the properties of the tested fluids. For the range of timescales of the experiments, no settling of the seeding particles was expected. The other components of the PIV apparatus included: optical components for the formulation of the thin laser sheet $(<2 \mathrm{~mm})$, a desktop computer with a programmable timing unit, PTU (LaVision), for the reliable synchronisation of the external devices (laser, CCD camera) and software (DaVis 8.2.2, LaVision) for data acquisition, processing and visualisation.

Through DaVis software, 2D images of the instantaneous and temporally averaged flow fields, including velocity vectors, are generated. Each $2 \mathrm{D}$ velocity vector was calculated from an interrogation window of $32 \times 32$ pixel with a 75\% overlap. The field of view (mask) for the PIV measurements was $39.2 \mathrm{~mm} \times 39.2 \mathrm{~mm}$, slightly smaller than the square windows, since the data close to the edges of the window, where light reflections could affect the reliability of the results, are neglected. In Fig. 2b, the field of view (blue-coloured square) and the Cartesian coordinates for the analysis of the PIV results are depicted. The applied mask provides access to the flow field established in a square area located $25.5 \mathrm{~mm}$ above the lower free surface of the cell and $35.5 \mathrm{~mm}$ below the upper free surface of the cell and $30.5 \mathrm{~mm}$ away from the vertical lateral walls.

\section{Nanofluid preparation}

For the study of the underlying physical mechanisms, "pure" nanofluids, without employing the electrostatic or steric stabilisation methods, were prepared. Dilute $\mathrm{Al}_{2} \mathrm{O}_{3}-$ $\mathrm{H}_{2} \mathrm{O}$ nanofluids with a mean concentration of $\varphi_{\mathrm{v}-}$ $=0.00026$ vol. $\%$ were synthesised by following the twostep preparation method, reported in detail in [2]. High purity DI (deionised) water (grade 3, ISO 3696) was used with a nominal $\mathrm{pH}$ value of 6.9 . However, the presence of $\mathrm{CO}_{2}$ in the atmosphere and the addition of nanoparticles affected the $\mathrm{pH}$ of the nanofluids. The selected nanoparticles were 70:30 $\delta: \gamma \mathrm{Al}_{2} \mathrm{O}_{3}$ (44931, Alfa Aesar). They were spherical in shape, with an average particle size of $45 \mathrm{~nm}$, as verified by transmission electron microscopy (TEM) [36], and a particle density of $3965 \mathrm{~kg} \mathrm{~m}^{-3}$.

\section{Experimental procedure}

A constant temperature gradient between the heating and cooling plates of $\Delta T_{\mathrm{h}, \mathrm{c}}=63.2^{\circ} \mathrm{C}$ and a constant temperature of $T_{\mathrm{c}}=26.5^{\circ} \mathrm{C}$ at the cooling plate were the boundary conditions in the current experimental study. The system hence had two control parameters, Rayleigh, $\mathrm{Ra}=4.1 \times 10^{9}$, and Prandtl, $\operatorname{Pr}=3.1$, and two response parameters, Nusselt and $\mathrm{Nu}$, and temporally averaged velocities, $V_{\text {avg. }}$. PIV measurements were obtained at three different planes in the $\mathrm{z}$ direction of the coordinate system of Fig. 1b inside the cell to record the impact of nanoparticles on the three-dimensional flow structure and properties of the base fluid. The first plane was at the centre of the cell, $z=0$ (central plane), the second was at an absolute distance $z$ of $3 \pm 1 \mathrm{~mm}$ behind the centre (back plane) and the third was at an absolute distance $\mathrm{z}$ of $4 \pm 1 \mathrm{~mm}$ in front of the centre (front plane). The distances of the back and front planes from the central plane were deliberately asymmetric to evaluate the geometric symmetry and coherency of the LSC.

Two thousand independent pairs of images of the instantaneous flow over a long sampling time, at steady state conditions (reached after $3 \mathrm{~h}$ from onset of the experiment [2]), were recorded and processed, to produce the temporally averaged velocity measurements. Each laser pulse pair was emitted at a rate of $0.25 \mathrm{~Hz}$, with a time interval between the pulses of $24 \mathrm{~ms}$. Both water and nanofluid experiments were repeated at least four times to confirm the repeatability and reliability in the execution of the experiment. To minimise random uncertainties, the mean values of four repeated experiments per fluid and per plane are presented and compared. The fractional uncertainty in the mean of the spatially and temporally averaged absolute velocity is $\leq 2.6 \%$. Additional error analysis is provided in "Error analysis" section.

\section{Results and discussion}

The RB cell operates under the hard turbulent state, where the existence of a large-scale circulation (LSC) that spans the height of the RB cell is expected to develop, as it has been reported in the literature. Based on the geometry of the cell (shape and aspect ratio) and the tendency of the 
LSC to extend along its largest spatial distance that corresponds to the most stable mode [37], the large-scale coherent flow evolves along a diagonal plane of the cell [24, 28, 38-41]. Therefore, the reported planar PIV flow measurements are projections of the diagonal flow field on the measurement plane, as seen through the square window depicted in Fig. 2.

Figures 3-5 show contours of the temporally averaged absolute velocity for DI water and dilute $\mathrm{Al}_{2} \mathrm{O}_{3}-\mathrm{H}_{2} \mathrm{O}$ nanofluids under Ra of $4.1 \times 10^{9}$ at the back, central and front planes, respectively. In the same figures, velocity vectors with arrow lengths proportional to the velocity magnitude (the vector length equals the pixel displacement $\times 10)$ are also depicted. Firstly, based on the direction and magnitude of the velocity vectors, a single cellular coherent structure with a preferred clockwise motion-as seen in the 2D PIV images - is observed inside the RB cell. This structure, known as large-scale circulation (LSC), is
Fig. 3 Contours of the temporally averaged absolute velocity, along with velocity vectors with arrow lengths proportional to the velocity magnitude for (a) DI water and (b) a dilute $\mathrm{Al}_{2} \mathrm{O}_{3}-\mathrm{H}_{2} \mathrm{O}$ nanofluid under $\mathrm{Ra}$ of $4.1 \times 10^{9}$, in the back plane (a)

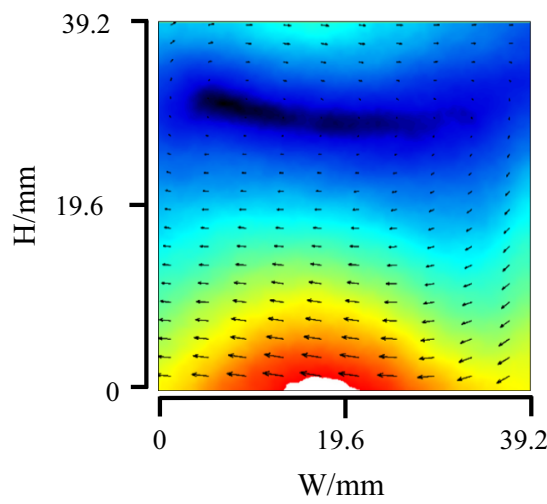

(a)

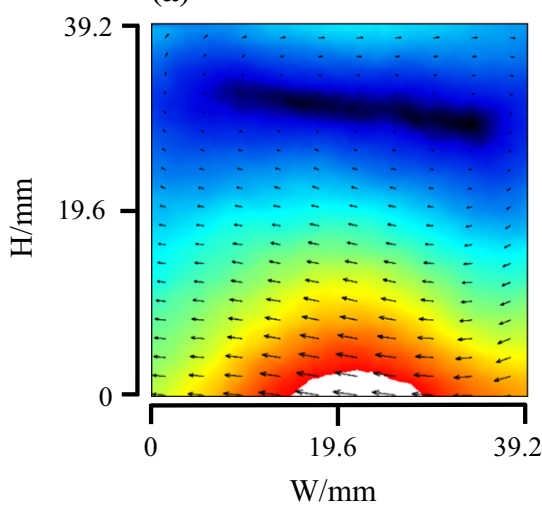

(a)

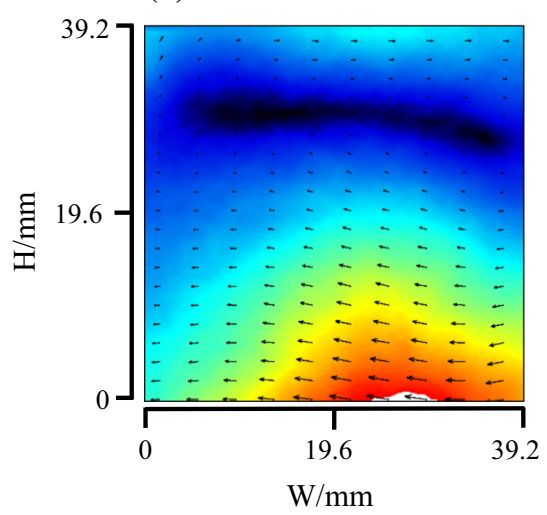

(b)

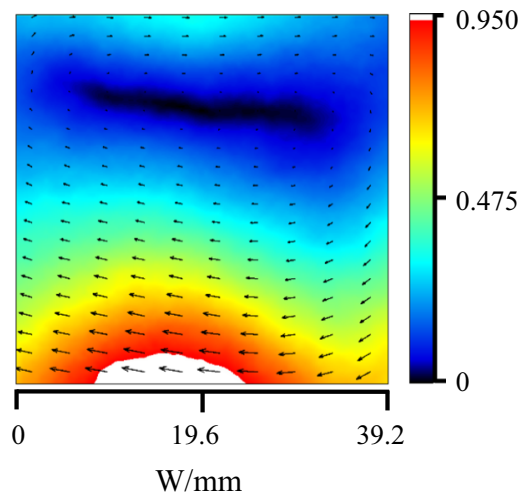

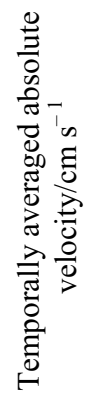

temporally averaged absolute velocity, along with velocity vectors with arrow lengths proportional to the velocity magnitude for (a) DI water and (b) a dilute $\mathrm{Al}_{2} \mathrm{O}_{3}-\mathrm{H}_{2} \mathrm{O}$ nanofluid under $\mathrm{Ra}$ of $4.1 \times 10^{9}$, in the central plane

Fig. 5 Contours of the temporally averaged absolute velocity, along with velocity vectors with arrow lengths proportional to the velocity magnitude for (a) DI water and (b) a dilute $\mathrm{Al}_{2} \mathrm{O}_{3}-\mathrm{H}_{2} \mathrm{O}$ nanofluid under $\mathrm{Ra}$ of $4.1 \times 10^{9}$, in the front plane

(b)
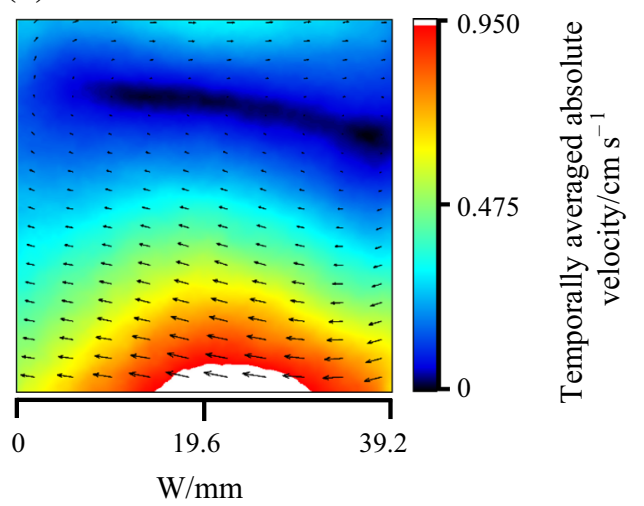

(b)

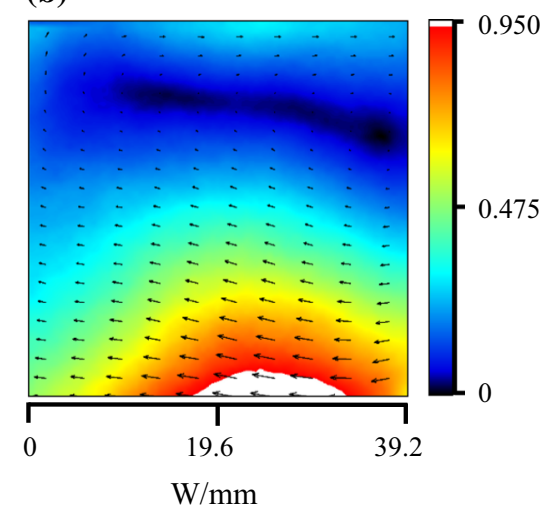


driven by hot plumes that congregate in an upwelling jet of fluid near the left-hand side and a downward jet of cold plumes that occur at the right-hand side of the field of view. Concerning the preferred orientation and direction of the LSC, no conclusive answer has been given so far, neither in cylindrical RB cells in which there is rotational symmetry, nor in cubic cells where the LSC evolves along the diagonals planes. Possible suggested reasons for the behaviour of the LSC include the effect of the earth's Coriolis force [42], a possible tilt of the cell relative to gravity and construction imperfections of the RB cells, mainly at the heating and cooling plates [42, 43].

By comparing the contours of the temporally averaged absolute velocity between DI water and dilute $\mathrm{Al}_{2} \mathrm{O}_{3}-\mathrm{H}_{2} \mathrm{O}$ nanofluids in all three planes, it can be clearly seen that the spatial distribution of the velocity flow field demonstrates differences between the tested fluids. Most notably, the area closer to the heating surface, where maximum velocities (in the field of view) are recorded, is notably larger for nanofluids than for water. To further evaluate the observations, the velocity characteristics for both fluids at all three planes are included and compared in Table 1.

Following earlier findings [44], it is reconfirmed that the maximum temporally averaged absolute velocity $|V|_{\text {avg-max }}$, the spatially and temporally averaged absolute velocity $\overline{|V|_{\text {avg }}}$ and the temporally and spatially averaged standard deviation of the turbulent velocity fluctuations Stdev are consistently higher for nanofluids than for DI water in the field of view. Additionally, it is demonstrated that this trend is consistent in all three planes, with the maximum difference between the velocity characteristics for DI water and nanofluid taking place at an absolute distance $\mathrm{z}$ of $4 \pm 1 \mathrm{~mm}$ (front plane) from the central plane. Starting with the central plane, the presence of nanoparticles is found to increase $\overline{|V|_{\text {avg }}}$ of the base fluid by
$2.7 \%$. As far as the back plane is concerned, the increase in $\overline{|V|_{\text {avg }}}, \delta|V|_{\text {avg }}$, is $7.2 \%$, while in the front plane this is $10.7 \%$. These differences are partially attributed to the increased $|V|_{\text {avg-max }}$ for nanofluids compared to DI water, close to the heating plate in the field of view. Due to that, it is also suggested that the range, minimum to maximum value, of the temporally averaged absolute velocity $|V|_{\text {avg }}$ is broader for nanofluids than for water. Since the PIV measurements were performed only in the bulk region of the turbulent Rayleigh-Bénard convection (RBC), the enhanced velocity characteristics are referred specifically to this area. However, the addition of nanoparticles to the base fluid could possibly expand, shrink or slightly shift the LSC with respect to the field of view.

In Table 2, the experimental conditions and the heat transfer performance of DI water and dilute $\mathrm{Al}_{2} \mathrm{O}_{3}-\mathrm{H}_{2} \mathrm{O}$ nanofluids are included. It is noted that the reported data are mean values out of 12 experiments (four experiments per plane), while the methodology for the heat transfer calculations is similar with that reported in previous work by the authors [2]. By comparing the general heat transfer, as expressed with the $\mathrm{Nu}$, no change is observed within the experimental uncertainty between water and nanofluids, thus verifying earlier PIV experiments conducted in a single plane close to the centre of the cubic RB cell under three different $\mathrm{Ra}$ [44].

Regardless of the enhanced temporally averaged flow velocity field in the bulk region of turbulent $\mathrm{RBC}$, no consistent trend for the general heat transport was noted for dilute $\mathrm{Al}_{2} \mathrm{O}_{3}-\mathrm{H}_{2} \mathrm{O}$ nanofluids. At the first glance, this finding seems consistent with the literature, where it has been reported that when the LSC is either suppressed or modified, no significant variation of the heat transport across the cell is expected [45]. This is on the basis that the heat transport is determined primarily by boundary layer

Table 1 Velocity characteristics for DI water and dilute $\mathrm{Al}_{2} \mathrm{O}_{3}-\mathrm{H}_{2} \mathrm{O}$ nanofluids at three parallel planes in the Rayleigh-Bénard cell, in the field of view

\begin{tabular}{|c|c|c|c|c|c|c|}
\hline \multirow[t]{2}{*}{ Plane } & \multicolumn{3}{|l|}{ DI water } & \multicolumn{3}{|c|}{$\mathrm{Al}_{2} \mathrm{O}_{3}-\mathrm{H}_{2} \mathrm{O}$ nanofluids } \\
\hline & $|V|_{\text {avg-max }} / \mathrm{cm} \mathrm{s}^{-1}$ & $\overline{\overline{|V|_{\mathrm{avg}}} / \mathrm{cm} \mathrm{s}^{-1}}$ & Stdev/cm s ${ }^{-1}$ & $|V|_{\mathrm{avg}-\max } / \mathrm{cm} \mathrm{s}^{-1}$ & 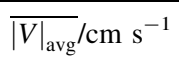 & $\overline{\mathrm{Stdev} / \mathrm{cm} \mathrm{s}^{-1} \text { ) }}$ \\
\hline Back & 0.9896 & 0.3311 & 0.2604 & 1.0401 & 0.3551 & 0.2651 \\
\hline Central & 1.0279 & 0.3444 & 0.2635 & 1.0595 & 0.3537 & 0.2673 \\
\hline Front & 0.9738 & 0.3115 & 0.2578 & 1.0342 & 0.3449 & 0.2662 \\
\hline
\end{tabular}

Table 2 Experimental conditions and heat transfer performance of DI water and dilute $\mathrm{Al}_{2} \mathrm{O}_{3}-\mathrm{H}_{2} \mathrm{O}$ nanofluids

\begin{tabular}{|c|c|c|c|c|c|}
\hline $\mathrm{Ra}\left(\times 10^{9}\right)$ & $\operatorname{Pr}$ & Testing fluid & $q^{\prime \prime} / \mathrm{kW} \mathrm{m}{ }^{-2}$ & $h / \mathrm{W} \mathrm{m}{ }^{-2} \mathrm{~K}^{-1}$ & $\mathrm{Nu}$ \\
\hline \multirow[t]{2}{*}{4.1} & 3.1 & DI water & 31.38 & 497 & 76.3 \\
\hline & & $\mathrm{Al}_{2} \mathrm{O}_{3}-\mathrm{H}_{2} \mathrm{O}$ nanofluid & 31.59 & 500 & 76.6 \\
\hline
\end{tabular}


instabilities rather than the structure of the LSC [46]. On the other hand, due to the enhanced thermal properties of nanofluids, one would expect enhancement of heat transfer, especially since no nanoparticle sedimentation or other deteriorating mechanism was noticed. A possible explanation could be the very small concentration of nanoparticles in the base fluid-although notable heat transfer enhancement has been reported for dilute nanofluids in the literature [47-49] - in combination with the experimental uncertainty and the construction of the RB cell. For instance, it has been noted that the side walls of the RB cell usually carry a significant part of the heat current. Therefore, the heat exchange between the fluid and the side walls will affect the fluid flow [50] and the general heat transport calculation [51]. Another possible reason could be the modified dynamics of the thermal plumes at the boundary layer due to the addition of nanoparticles to the base fluid. Additional numerical and experimental investigations are required to assess the heat and mass transfer phenomena that occur at the whole volume of a RB cell, including the boundary layers.

\section{Error analysis}

To ensure reliability of the reported results and identify any systematic uncertainties induced by the PIV technique or the experimental methodology, all the experiments were repeated at least four times. For the uncertainties in the mean values, the methodology of Kirkup [52] was followed. Table 3 presents the four individual values of the Nusselt number and the spatially and temporally averaged absolute velocity for DI water and dilute $\mathrm{Al}_{2} \mathrm{O}_{3}-\mathrm{H}_{2} \mathrm{O}$ nanofluids in the central plane. In the same table, the mean (out of four experiments) values are included. At first, it can be seen the values for each fluid are very close to each other with the uncertainty in the mean being very small. By following the same procedure for the rest two planes, the fractional uncertainty in the mean of the Nusselt number is $<1.0 \%$, and the fractional uncertainty in the mean of the

Table 3 Repeatability test for DI water and dilute $\mathrm{Al}_{2} \mathrm{O}_{3}-\mathrm{H}_{2} \mathrm{O}$ nanofluids at the central plane

\begin{tabular}{llllll}
\hline Experiment & \multicolumn{2}{l}{ DI water } & & \multicolumn{2}{l}{$\mathrm{Al}_{2} \mathrm{O}_{3}-\mathrm{H}_{2} \mathrm{O}$ nanofluids } \\
\cline { 2 - 3 } \cline { 5 - 6 } & $\mathrm{Nu}$ & $\overline{|V|_{\text {avg }}} / \mathrm{cm} \mathrm{s}^{-1}$ & & $\mathrm{Nu}$ & $\overline{|V|_{\text {avg }}} / \mathrm{cm} \mathrm{s}^{-1}$ \\
\hline 1st & 76.9 & 0.3455 & & 77.4 & 0.3494 \\
2nd & 77.6 & 0.3528 & & 77.0 & 0.3479 \\
3rd & 75.3 & 0.3465 & & 76.1 & 0.3560 \\
4th & 75.1 & 0.3326 & 74.6 & 0.3617 \\
Mean & 76.2 & 0.3444 & 76.3 & 0.3537 \\
\hline
\end{tabular}

spatially and temporally averaged absolute velocity is $\leq 2.6 \%$. As far as the nominal uncertainty of the PIV measurements is concerned, it is related to the minimum detectable pixel shift according to the employed camera and the selected calculation parameters. For the values of the spatially and temporally averaged velocity employed in the current study, the minimum detectable shift corresponds to $\leq 0.0007 \mathrm{~cm} \mathrm{~s}^{-1}$ or $\approx 0.2 \%$. Therefore, the results presented herein are repeatable, reliable and precise.

\section{Conclusions}

In this study, the heat and mass transfer behaviour of dilute $\mathrm{Al}_{2} \mathrm{O}_{3}-\mathrm{H}_{2} \mathrm{O}$ nanofluids under turbulent natural convection in a cubic Rayleigh-Bénard (RB) cell with optical access was experimentally investigated. A high-spatial-resolution flow velocimetry method, particle image velocimetry (PIV), was employed to measure the flow velocity at three parallel planes inside the RB cell for both DI water and nanofluids. The nanofluid results were compared with those of DI water that was used as a benchmark. Following earlier PIV experiments [44], it was confirmed that the addition of a small amount of $\mathrm{Al}_{2} \mathrm{O}_{3}$ nanoparticles to DI water, $\varphi_{\mathrm{v}}=0.00026 \mathrm{vol} . \%$, modifies the mass transfer behaviour of the base fluid in the field of view, under hard turbulence-Rayleigh number of the order of $10^{9}$. It was demonstrated that the maximum temporally averaged absolute velocity $|V|_{\text {avg-max }}$ and the spatially and temporally averaged absolute velocity $\overline{|V|_{\text {avg }}}$ are higher for nanofluids compared to DI water at all three planes inside the RB cell. Despite the enhanced velocity characteristics in the bulk region of turbulent natural convection, no alteration of the heat transfer performance of the base fluid was noticed with the addition of nanoparticles. Possible reasons include the small nanoparticle loading in the base fluid and the questionable contribution of the large-scale circulation on the heat transfer rate. Finally, the altered dynamics of the thermal plumes at the boundary layer due to the presence of nanoparticles in the base fluid cannot be excluded as a counteracting mechanism. The current work assesses the heat and mass transfer behaviour of nanofluids under turbulent Rayleigh-Bénard convection in an attempt to evaluate the applicability of nanofluids to cooling applications.

Acknowledgements This work was funded by the RCUK Energy Program and EURATOM. The views and opinions expressed herein do not necessarily reflect those of the European Commission. We are grateful to CCFE for the financial support through the CASE EPSRC studentship that allowed this research and especially Dr. Thomas Barrett for his input to this project. Data supporting this publication can be obtained by request from MultiphaseFlows@imperial.ac.uk. 
"Funding was provided by Engineering and Physical Sciences Research Council".

Open Access This article is distributed under the terms of the Creative Commons Attribution 4.0 International License (http://creative commons.org/licenses/by/4.0/), which permits unrestricted use, distribution, and reproduction in any medium, provided you give appropriate credit to the original author(s) and the source, provide a link to the Creative Commons license, and indicate if changes were made.

\section{References}

1. Buongiorno J. Convective transport in nanofluids. J Heat Transf. 2006;128(3):240-50.

2. Kouloulias K, Sergis A, Hardalupas Y. Sedimentation in nanofluids during a natural convection experiment. Int $\mathrm{J}$ Heat Mass Transf. 2016;101:1193-203.

3. Murshed SMS, Leong KC, Yang C, Nguyen N-T. Convective heat transfer characteristics of aqueous $\mathrm{TiO}_{2}$ nanofluid under laminar flow conditions. Int J Nanosci. 2008;7(06):325-31.

4. Baby TT, Sundara R. Synthesis and transport properties of metal oxide decorated graphene dispersed nanofluids. J Phys Chem C. 2011;115(17):8527-33.

5. Murshed SMS, Nieto de Castro CA, Lourenço MJV, Lopes MLM, Santos FJV. A review of boiling and convective heat transfer with nanofluids. Renew Sustain Energy Rev. 2011;15(5):2342-54

6. Taylor R, Coulombe S, Otanicar T, Phelan P, Gunawan A, Lv W, et al. Small particles, big impacts: a review of the diverse applications of nanofluids. J Appl Phys. 2013;113(1):011301.

7. Estellé P, Halelfadl S, Maré T. Thermophysical properties and heat transfer performance of carbon nanotubes water-based nanofluids. J Therm Anal Calorim. 2016;127(3):2075-81.

8. Elsheikh AH, Sharshir SW, Mostafa ME, Essa FA, Ahmed Ali MK. Applications of nanofluids in solar energy: a review of recent advances. Renew Sustain Energy Rev. 2018;82:3483-502.

9. Sergis A, Hardalupas Y. Anomalous heat transfer modes of nanofluids: a review based on statistical analysis. Nanoscale Res Lett. 2011;6(1):391.

10. Minea AA. Comparative study of turbulent heat transfer of nanofluids. J Therm Anal Calorim. 2015;124(1):407-16.

11. Xuan Y, Li Q. Investigation on convective heat transfer and flow features of nanofluids. J Heat Transf. 2003;125(1):151.

12. Nayak AK, Gartia MR, Vijayan PK. An experimental investigation of single-phase natural circulation behavior in a rectangular loop with $\mathrm{Al}_{2} \mathrm{O}_{3}$ nanofluids. Exp Therm Fluid Sci. 2008;33(1):184-9.

13. Hemmat Esfe M, Saedodin S. Turbulent forced convection heat transfer and thermophysical properties of Mgo-water nanofluid with consideration of different nanoparticles diameter, an empirical study. J Therm Anal Calorim. 2015;119(2):1205-13.

14. Ma Y, Mohebbi R, Rashidi MM, Yang Z. Study of nanofluid forced convection heat transfer in a bent channel by means of lattice Boltzmann method. Phys Fluids. 2018;30(3):032001.

15. Haddad Z, Oztop HF, Abu-Nada E, Mataoui A. A review on natural convective heat transfer of nanofluids. Renew Sustain Energy Rev. 2012;16(7):5363-78.

16. Savithiri S, Pattamatta A, Das SK. A single-component nonhomogeneous lattice boltzmann model for natural convection in $\mathrm{Al}_{2} \mathrm{O}_{3}$ /water nanofluid. Numer Heat Transf A Appl. 2015;68(10):1106-24.

17. Ho CJ, Chen MW, Li ZW. Numerical simulation of natural convection of nanofluid in a square enclosure: effects due to uncertainties of viscosity and thermal conductivity. Int $\mathrm{J}$ Heat Mass Transf. 2008;51(17-18):4506-16.

18. Boualit A, Zeraibi N, Chergui T, Lebbi M, Boutina L, Laouar S. Natural convection investigation in square cavity filled with nanofluid using dispersion model. Int $\mathbf{J}$ Hydrogen Energy. 2017;42(13):8611-23.

19. Hafad Bara E, El Hamdani S, Bendou A, Limam K. Parametric study on natural convection of nanofluids in a heated chamber. Energy Proc. 2017;139:424-9.

20. Li CH, Peterson GP. Experimental studies of natural convection heat transfer of $\mathrm{Al}_{2} \mathrm{O}_{3} / \mathrm{DI}$ water nanoparticle suspensions (nanofluids). Adv Mech Eng. 2010;2:742739.

21. Wen D, Ding Y. Natural convective heat transfer of suspensions of titanium dioxide nanoparticles (nanofluids). IEEE Trans Nanotechnol. 2006;5(3):220-7.

22. Ni R, Zhou S-Q, Xia K-Q. An experimental investigation of turbulent thermal convection in water-based alumina nanofluid. Phys Fluids. 2011;23(2):022005.

23. Ilyas SU, Pendyala R, Narahari M. An experimental study on the natural convection heat transfer in rectangular enclosure using functionalized alumina-thermal oil-based nanofluids. Appl Therm Eng. 2017; 127:765-75.

24. Xia KQ, Sun C, Zhou SQ. Particle image velocimetry measurement of the velocity field in turbulent thermal convection. Phys Rev E. 2003;68(6):066303.

25. Fernando HJS. Handbook of environmental fluid dynamics, volume one: overview and fundamentals. Boca Raton: Taylor \& Francis Group; 2013.

26. Rohsenow WM, Harnett JP, Cho YI. Handbook of heat transfer. 3rd ed. New York: McGraw-Hill; 1998.

27. Heslot F, Castaing B, Libchaber A. Transitions to turbulence in helium gas. Phys Rev A. 1987;36(12):5870-3.

28. Zocchi G, Moses E, Libchaber A. Coherent structures in turbulent convection, an experimental study. Phys A. 1990;166(3):387-407.

29. Castaing B, Gunaratne G, Heslot F, Kadanoff L, Libchaber A, Thomae S, et al. Scaling of hard thermal turbulence in RayleighBénard convection. J Fluid Mech. 2006;204:1-30.

30. Krishnamurti R, Howard LN. Large-scale flow generation in turbulent convection. Proc Natl Acad Sci USA. 1981;78(4):1981-5.

31. Sano M, Wu XZ, Libchaber A. Turbulence in helium-gas free convection. Phys Rev A. 1989;40(11):6421-30.

32. Qiu XL, Tong P. Large-scale velocity structures in turbulent thermal convection. Phys Rev E. 2001;64:036304.

33. Shang XD, Qiu XL, Tong P, Xia KQ. Measured local heat transport in turbulent Rayleigh-Benard convection. Phys Rev Lett. 2003;90(7):074501.

34. Sergis A, Hardalupas Y, Barrett TR. Potential for improvement in high heat flux HyperVapotron element performance using nanofluids. Nucl Fus. 2013;53(11):113019.

35. Dominguez-Ontiveros E, Fortenberry S, Hassan YA. Experimental observations of flow modifications in nanofluid boiling utilizing particle image velocimetry. Nucl Eng Des. 2010;240(2):299-304.

36. Kouloulias K, Sergis A, Hardalupas Y, editors. The influence of nanofluid $\mathrm{pH}$ on natural convection. In: 12th International conference on heat transfer, fluid mechanics and thermodynamics (HEFAT2016); 11-13 July 2016; Costa del Sol, Spain.

37. Sun C, Xia KQ, Tong P. Three-dimensional flow structures and dynamics of turbulent thermal convection in a cylindrical cell. Phys Rev E. 2005;72:026302.

38. Qiu XL, Xia KQ. Viscous boundary layers at the sidewall of a convection cell. Phys Rev E. 1998;58(1):486-91. 
39. Aziz K. Numerical solution of the three-dimensional equations of motion for laminar natural convection. Phys Fluids. 1967;10(2):314-24.

40. Foroozani N, Niemela JJ, Armenio V, Sreenivasan KR. Influence of container shape on scaling of turbulent fluctuations in convection. Phys Rev E. 2014;90(6):063003.

41. Foroozani N, Niemela JJ, Armenio V, Sreenivasan KR. Reorientations of the large-scale flow in turbulent convection in a cube. Phys Rev E. 2017;95(3-1):033107.

42. Brown E, Ahlers G. Effect of the earth's coriolis force on the large-scale circulation of turbulent Rayleigh-Bénard convection. Phys Fluids. 2006;18(12):125108.

43. Weiss S, Ahlers G. Effect of tilting on turbulent convection: cylindrical samples with aspect ratio $\Gamma=0.50$. J Fluid Mech. 2013;715:314-34.

44. Kouloulias K, Sergis A, Hardalupas Y, Barrett TR. Measurement of flow velocity during turbulent natural convection in nanofluids. Fus Eng Des. 2017;123:72-6.

45. Ciliberto S, Cioni S, Laroche C. Large-scale flow properties of turbulent thermal convection. Phys Rev E. 1996;54(6):R5901-4.

46. Ahlers G, Grossmann S, Lohse D. Heat transfer and large scale dynamics in turbulent Rayleigh-Bénard convection. Rev Mod Phys. 2009;81(2):503-37.
47. Murshed SMS, Milanova D, Kumar R, editors. An experimental study of surface tension-dependent pool boiling characteristcs of carbon nanotubes-nanofluids. In: Proceedings of the ASME 2009 7th international conference on nanochannels, microchannels and minichannels (ICNMM2009); June 22-24, 2009; Pohang, South Korea.

48. Kumar DH, Patel HE, Kumar VR, Sundararajan T, Pradeep T, Das SK. Model for heat conduction in nanofluids. Phys Rev Lett. 2004;93(14):144301.

49. Patel HE, Das SK, Sundararajan T, Sreekumaran Nair A, George B, Pradeep T. Thermal conductivities of naked and monolayer protected metal nanoparticle based nanofluids: manifestation of anomalous enhancement and chemical effects. Appl Phys Lett. 2003;83(14):2931-3.

50. Brown E, Nikolaenko A, Funfschilling D, Ahlers G. Heat transport in turbulent Rayleigh-Bénard convection: effect of finite top-and bottom-plate conductivities. Phys Fluids. 2005;17(7):1-10.

51. Ahlers G. Effect of sidewall conductance on heat-transport measurements for turbulent Rayleigh-Benard convection. Phys Rev E. 2001;63:015303.

52. Kirkup L. Experimental methods: an introduction to the analysis and presentation of data. Hoboken: Wiley; 1994. 